Expl Agric. (2014), volume 50 (3), pp. 458-479 @ Cambridge University Press 2013. The online version of this article is published within an Open Access environment subject to the conditions of the Creative Commons Attribution licence http://creativecommons.org/licenses/by/3.0/

doi:10.1017/S001447971300063X

\title{
EFFECT OF SOIL DRYING ON RATE OF STRESS DEVELOPMENT, LEAF GAS EXGHANGE AND PROLINE AGGUMULATION IN ROBUSTA GOFFEE (COFFEA CANEPHORA PIERRE EX FROEHNER) GLONES
}

\author{
By S. G. TESFAYE ${ }^{\dagger}$, M. R. ISMAIL ${ }^{\ddagger}$, M. F. RAMLAN ${ }^{\S}$, M. MARZIAH $^{\ddagger \dagger \dagger}$ \\ and $\mathrm{H}$. KAUSAR ${ }^{\ddagger}$ \\ $\dagger$ Jima Agricultural Research Center, Ethiopian Institute of Agricultural Research, P.O. Box 192, \\ Fima, Ethiopia, ${ }^{\ddagger}$ Laboratory of Food Crops, Institute of Tropical Agriculture, Universiti Putra \\ Malaysia, 43400 Serdang, Selangor, Malaysia, ${ }^{\S}$ Department of Crop Science, Faculty of \\ Agriculture, Universiti Putra Malaysia, 43400 Serdang, Selangor, Malaysia and ${ }^{\dagger \dagger}$ Faculty of \\ Biotechnology and Biomolecular Sciences, Universiti Putra Malaysia, 43400 Serdang, Selangor, \\ Malaysia
}

(Accepted 13 October 2013; First published online 2 December 2013)

\begin{abstract}
SUMMARY
Seasonal drought stresses as a result of changes in global climate and local weather conditions are among the major factors adversely affecting growth and productivity of Robusta coffee (Coffea canephora pierre ex froehner) in many areas producing the crop. It is believed that there exists a wide range of genetic variability among Robusta coffee clones for traits associated with drought tolerance. Therefore, in an attempt to determine differences among Robusta coffee clones for some growth, physiological and biochemical parameters and identify drought-tolerant materials, 12 months old seedlings of six clones (IC-2, IC-3, IC4, IC-6, IC-8 and R-4) were subjected to two treatments: well-watered control and drought-stressed (soil drying) by withholding irrigation for three weeks in a rain shelter at University Putra Malaysia, Malaysia. The rate of stress development, expressed as extent of wilting and damage to leaves, was considerably higher for clones IC-8, IC-4, R-4 and IC-2 than for IC-3 and IC-6 during the stress period. Leaf water potential (LWP), stomatal conductance $\left(g_{s}\right)$ and rate of net photosynthesis $\left(P_{\mathcal{N}}\right)$ progressively decreased but leaf proline (LP) concentration substantially increased with time of exposure of the plants to soil drying. There was a considerable difference between coffee clones for the rate of change in these parameters. All the clones except IC-6 and IC-8 showed a negative carbon balance with the most negative value for R-4 at the end of the stress period. Six days after rewatering, LWP, $g_{s}$ and $P_{\mathcal{N}}$ increased rapidly while LP concentration decreased and reached a level equivalent to those of well-watered plants, especially for clones IC-3 and IC-6. Among the drought-stressed plants, IC-6 and IC-3 had still significantly higher shoot growth, total dry matter yield and root to shoot ratio than did IC-2, IC-4, IC-8 and R-4. In general, clones IC-6 and IC-3 exhibited quite a better performance in almost all the parameters considered in this study and seemed to be less sensitive to drought stress. Hence, drought tolerance attributes in these clones could be linked to a more effective osmotic adjustment due to more rapid accumulation of LP and probably some morphological parameters, such as increased root-to-shoot ratio. However, further analyses at molecular level, detail biochemical studies and observations under diverse field conditions are required to come up with more conclusive recommendations.
\end{abstract}

ๆCorresponding author. Email: razi@agri.upm.edu.my 
Coffee is one of the most important commodities in the world market and it plays a significant role in the national economy of many developing countries. Among the economically important species of the genus Coffea, Robusta coffee (C. canephora Pierre ex Froehner) accounts for about $20 \%$ of the total coffee trade in the world market (Willson, 1999). However, its production is greatly affected by frequent drought stress, specially in areas with long dry spells. It is believed that there exists a wide range of genetic variability among Robusta coffee clones for morphological, physiological and biochemical traits associated with drought tolerance (Anim-Kwapong et al., 2011; Lima et al., 2002). Besides morphological stress avoidance or tolerance mechanisms, such as decline in shoot growth and leaf area and increase in leaf thickness and root to shoot ratio with soil moisture depletion (Abernethy and McManus, 1998; Rhizopoulou et al., 1991; Volkmar and Woodbury, 1995), stomatal closure and the rate of decline in leaf water potential (LWP) and net photosynthesis $\left(P_{\mathcal{N}}\right)$ (Price et al., 1992) are also regarded as sensitive physiological indicators of the ability of a genotype to adapt stress conditions (Loewenstein and Pallardy, 1998a, b; Saliendra et al., 1995).

On the other hand, it has been reported that leaf scorching (damage to leaves due to water deficit stress) was inversely related to shoot growth parameters and can be used as an important attribute to screen Robusta coffee clones for drought tolerance (AnimKwapong et al., 2011). Because of its role in osmotic adjustment (OA), the accumulation of proline in plant tissues under water deficit condition has also been considered as one of the adaptive mechanisms in drought-tolerant genotypes (Heuer, 1999; Ismail et al., 1994; Maestri et al., 1995). In fact, Lima et al. (2002) and Anim-Kwapong et al. (2011) have reported the existence of large diversity among Robusta coffee genotypes around the world for drought tolerance, although these variabilities have not been well studied and documented in relation to physiological and biochemical traits.

The major objective of this study was, therefore, to determine differences between six widely grown Robusta coffee clones for some morphological, physiological and biochemical parameters associated with drought tolerance and to identify the most important mechanisms involved in the process of tolerance.

\section{MATERIALS AND METHODS}

\section{Plant material}

Six clones of C. canephora Pierre ex Froehner (clones IC-2, IC-3, IC-4, IC-6, IC-8 and $\mathrm{R}-4$ ), which are widely grown by local coffee farmers in the Northern part of Malaysia, were used in this experiment. The plants were grown in pots (with a diameter of 20 $\mathrm{cm}$ and a height of $25 \mathrm{~cm}$ ) filled with a mixture of top soil (Serdang series), manure and sand (3:2:2 ratio by volume), irrigated daily and fertilized with 20-g NPK per pot during establishment. When the plants were 12 months old, drought stress was imposed by withholding irrigation until severe wilting symptoms were observed. 


\section{Treatment and plot arrangement}

Seventy-two uniformly grown seedlings were selected from each clone and arranged in six plots each consisting of 12 plants (three well-watered (control) and three droughtstressed plots). Each drought-stressed plot was further sub-divided into two plots, each with six plants. One-half of the plot was rewatered when the seedlings showed severe wilting symptoms just 12 days after withholding irrigation and the rate of recovery in LWP, $g_{s}$ and $P_{\mathcal{N}}$, and changes in leaf proline (LP) concentration were measured. The other half of the plot was further maintained under drought stress condition for nine days to see changes in the degree of leaf folding or wilting, rate of leaf fall, loss of total leaf area and total dry matter yield and proportion of plants recovering upon rewatering after 21 days of soil drying, while the plants in the control plots were watered every other day throughout the experiment period. Besides, plant height, main stem diameter (girth), total leaf area, total dry matter yield and root to shoot ratio were also measured in the second set of experiment just after 21 days of soil drying. On the other hand, 18 uniformly grown seedlings were selected from well-watered plots of each clone, arranged as six plants per plot and planted out in larger pots (with $100-\mathrm{cm}$ diameter and 100-cm height, open at both upper and bottom sides and filled with top soil (Serdang series) from the field) and maintained under rain-fed field condition to see their growth performance (plant height, girth and canopy diameter) and sensitivity to dry spells.

\section{Study design and site description}

The experiment was carried out in a randomized complete block design (RCBD) with three replicates of 12 factorial treatment combinations (two water regimes $\times$ six clones) in a rain shelter with average midday photosynthetic photon flux density (PPFD) of $672.3 \mu \mathrm{mol} \mathrm{m}{ }^{-2} \mathrm{~s}^{-1}$ and air temperature and relative humidity $(\mathrm{RH})$ of $34.5^{\circ} \mathrm{C}$ and $62.9 \%$, respectively. The rain shelter was located at the Hydroponics Unit of Universiti Putra Malaysia (UPM), Serdang, Selangor, Malaysia $\left(3^{\circ} 02^{\prime} \mathrm{N} ; 101^{\circ} 42^{\prime}\right.$ $\mathrm{E}$ and $31 \mathrm{~m}$ above sea level). The open field observation under rain-fed condition was also carried out in RCBD with three replications of six clones. The mean maximum and minimum temperatures at UPM during the study period were $32.4^{\circ} \mathrm{C}$ and $22.8{ }^{\circ} \mathrm{C}$, respectively, with mean relative humidity of $65.5 \%$.

\section{Sampling procedure and data collection}

Leaf water potential, stomatal conductance $\left(g_{s}\right), P_{\mathcal{N}}$ and LP concentration were measured on fully expanded leaves on the third and fourth nodes from the apex of plageotropic branches. On each sampling date, measurements were taken during noon hours (between 1100 and 1300 hours) under clear sky conditions during the stress period and after rewatering.

\section{Leaf gas exchange}

Rate of net $P_{\mathcal{N}}$ was measured at four-day intervals, using a portable infrared gas analyzer (Port. Li-6200 Photosynthesis System, Licor, Lincoln, Nebraska, USA). LWP 
and $g_{s}$ were measured every three days on similar leaf samples as used for $P_{\mathcal{N}}$. LWP was determined with a pressure chamber (PMS, Soil Moisture Equipment, Santa Barbara, USA), while $g_{s}$ was measured using diffusive porometer (AP-4, Delta T Devices Ltd., Cambridge, UK).

\section{Proline assay}

The accumulation of free proline in coffee leaves was determined at three-day intervals following the procedure described by Bates et al. (1973). Fully expanded leaves (same as those used for measuring LWP, $g_{s}$ and $P_{\mathcal{N}}$ ) were excised and used for the determination of LP concentration. LP content was measured using 0.5 -g sample of fresh leaves. The samples were homogenized in $10 \mathrm{ml}$ of $3 \%$ aqueous sulfosalicylic acid and filtered through Whatman No. 2 paper. Then $2 \mathrm{ml}$ of filtrate was mixed with $2 \mathrm{ml}$ of acid-ninhydrin and $2 \mathrm{ml}$ of glacial acetic acid and heated at $100^{\circ} \mathrm{C}$ for $1 \mathrm{~h}$ under water bath condition. Then the reaction was terminated in an ice bath for 10 min; then $4 \mathrm{ml}$ of toluene was added to the mixture and contents of test tubes were stirred for 15 to $30 \mathrm{~s}$. The chromophore was aspirated from the aqueous phase, and the absorbance was read at $520 \mathrm{~nm}$ using toluene as a blank (Parimala and Muthuchelian, 2011 ; Siamak et al., 2012).

\section{Leaffolding and rate of leaffall}

The rate of drought stress development in the plant, expressed as the extent of leaf folding or wilting and damage on leaves (leaf scorching) at noon hours (between 1200 and 1300 hours) and early in the morning (at 0600 hours before sun rise), was estimated by visual scoring at three-day intervals, with values ranging between 1 and 5 as described by Rosario et al. (1992) and Anim-Kwapong et al. (2011) (scored using 1 to 5 scale, where 1: indicating all leaves green and turgid, 2: most leaves still turgid except the youngest which show leaf folding at noon and recover during the night time, 3: all leaves wilt and/or show leaf folding and do not recover during the night time (symptoms of senescence evident), 4: leaves (specially the older ones) turning pale green, showing severe wilting or folding and partially dry and 5: leaves turning brown and dry, mostly drooping). Each plant in a drought-stressed plot was evaluated during visual rating and the sum of scores on individual plants was divided by the number of plants in the plot to estimate the mean values per plot in each replication. Besides, the proportion of plants which exhibited wilting symptoms was also calculated based on counts taken every three days, and the percentage of plants recovering was also calculated based on counts taken two weeks after the commencement of rewatering on day 21 for each drought-stressed plot. All the plants in drought-stressed plots were considered to determine rate of leaf fall at the end of the stress cycle and rate of recovery (initiation of new flushes) upon rewatering after 21 days of withholding irrigation. The extent of leaf shedding or rate of leaf fall was calculated as the proportion of dried and fallen leaves from the total number of leaves produced by the plant. 
Vegetative growth parameters and total dry matter yield

Plant height, girth (stem diameter at the base of the main stem), total leaf area and total dry matter yield were measured using two randomly selected seedlings from each plot at the end of the experiment. Total green leaf area of sampled plants was measured using an automatic leaf area meter (Delta T Device, Cambridge, UK). Loss of total leaf area and total dry matter production due to soil drying was estimated based on the respective green leaf area and total dry matter yield of plants in drought-stressed and well-watered plots just 21 days after withholding irrigation. Plants sampled from each plot were separated into shoot part (leaves, stem and branches) and roots and dried in an oven at $80{ }^{\circ} \mathrm{C}$ to a constant weight. Then each plant part was weighed to determine total dry matter yield and root to shoot ratio at the end of the stress period.

On the other hand, growth parameters for the field observation were measured using three randomly selected plants from each plot. Plant height (from soil surface to tip of the main stem), girth (main stem diameter at $10 \mathrm{~cm}$ height from the soil surface) and canopy diameter (from the tip of the longest primary branch at one side to the tip of the longest primary branch at the opposite side of the shoot) were measured 18 months after transplanting, while mean sensitivity to drought was scored using visual rating (1-5 scale, as described above) on all the plants in each plot at peak dry spells during this period.

\section{Statistical analysis}

All the variables measured in the course of the study were analysed using the SAS statistical software (SAS Institute Inc., 1988).

\section{RESULTS}

\section{Leaf water potential}

Leaf water potential progressively decreased from less than -1.0 to $-3.4 \mathrm{MPa}$ with time of exposure of coffee plants to soil drying. The rate of decline in LWP was much higher and faster at later stages (after six days) than at the early stages of stress development. There was also a considerable difference between coffee clones for LWP. The rate of decline in LWP was lower in clone $\mathrm{IC}-2$, IC-4, IC-8 and R-4 than in IC3 and IC-6 just three days after withholding irrigation. Six days after withholding irrigation, the rate of reduction in LWP was still lower in IC-2, IC-4, IC-8 and R-4 than in IC-3 and IC-6, where it was decreased by about 75\% compared with the controls. In general, LWP decreased to the lowest value for all the clones at the end of the stress period on day 12 (Table 1). On the other hand, clones IC-8, IC-6 and IC-2 had considerably higher LWP under well-watered condition (Figure 1).

After rewatering, LWP of IC-2, IC-3, IC-4 and IC-6 rapidly increased within three days and it reached a level equivalent to that of well-watered plants $(>-1.0 \mathrm{MPa})$, especially for IC-3 and IC-6 just six days after rewatering. In general, IC-3 and IC-6 showed significantly faster rate of recovery than did other clones upon rewatering at the end of the soil drying cycle. On the other hand, IC-8 and R-4 exhibited a slower 
Table 1. Leaf water potential (LWP), stomatal conductance $\left(g_{s}\right)$, rate of net photosynthesis $\left(P_{\mathcal{N}}\right)$, leaf proline concentration (LPG), sensitivity as estimated by visual stress score values (SSV) and proportion of plants showing complete wilting symptoms (PPCWS) on day 12 of soil drying.

\begin{tabular}{lcccccc}
\hline Clone & $\begin{array}{c}\text { LWP } \\
(\mathrm{MPa})\end{array}$ & $g_{s}\left(\mathrm{mmol} \mathrm{m}^{-2} \mathrm{~s}^{-1}\right)$ & $P_{\mathcal{N}}\left(\mu \mathrm{mol} \mathrm{m}^{-2} \mathrm{~s}^{-1}\right)$ & $\begin{array}{c}\mathrm{LPC}\left(\mu \mathrm{mol} \mathrm{g}^{-1}\right. \\
\text { fresh weight })\end{array}$ & $\begin{array}{c}\mathrm{SSV}(1-5 \\
\text { scale })\end{array}$ & $\begin{array}{c}\text { PPCWS } \\
(\%)\end{array}$ \\
\hline IC-2 & -3.2 & 5 & -0.4 & 10.0 & 3.10 & 96.80 \\
IC-3 & -3.2 & 7 & -0.8 & 12.2 & 2.50 & 86.80 \\
IC-4 & -3.4 & 5 & -0.4 & 9.4 & 3.33 & 96.80 \\
IC-6 & -3.3 & 4 & 0.8 & 13.3 & 2.33 & 86.80 \\
IC-8 & -3.3 & 5 & 0.4 & 9.0 & 3.33 & 96.80 \\
R-4 & -3.2 & 7 & -2.5 & 9.5 & 3.40 & 96.80 \\
\hline
\end{tabular}

rate of recovery and significantly lower values of LWP than did the other clones on day 3 and even six days after rewatering (Figure 1).

\section{Stomatal conductance}

Stomatal conductance of all coffee clones was substantially decreased as the intensity of water deficit stress increased with time of soil drying. Differences among the clones were also considerable at the initial stage (under well-watered condition) and on day 3 and 6 after the plants were subjected to soil drying. The rate of decline in $g_{s}$ was faster for clones IC-2, IC-4, IC-8 and R-4 (61-71\%) than for clones IC-3 and IC-6 (only 27-28\%) during the early stages of the stress period until day 3 . In general, $g_{s}$ of clones IC-3 and IC-6 decreased gradually at a relatively constant rate until day 9, and it was maintained at considerably higher level on day 3, compared with its mean values on the same day for the other clones. However, all the clones had a similar and the lowest value of $g_{s}$ on day 12 after withholding irrigation, where the stomata were nearly closed (Figure 2, Table 1).

There was also a considerable difference between coffee clones for $g_{s}$ after rewatering at the end of the soil drying period on day 12. In general, it was observed that clones IC-3 and IC-6 maintained significantly higher level of $g_{s}$ at a faster rate (on day 3) than did clones IC-2 and IC-4, which showed gradual recovery in $g_{s}$ within six days after rewatering. On the other hand, $g_{s}$ values of IC-8 and R-4 were not much improved by rewatering and was significantly lower than that of the other clones even on day 6 after rewatering. The $g_{s}$ values for drought-stressed plants of clones IC-3 and IC-6 were similar to those of the well-watered controls, but were slightly lower than the control values for clones IC-2 and IC-4 just six days after rewatering (Figure 2).

\section{Rate of photosynthesis}

There were considerable differences between coffee clones for the rate of $P_{\mathcal{N}}$ under both well-watered and drought-stressed conditions. Clone IC-6, followed by IC-8, had significantly higher rate of net $P_{\mathcal{N}}$ than did IC-2, IC-3, IC-4 and R-4 at the early stages of stress on day 4 after exposure of plants to soil drying. In general, water-deficit stress reduced the rate of net $P_{\mathcal{N}}$ by about $68 \%$ compared with the well-watered plants during the first week of the stress period. The decline in $P_{\mathcal{N}}$ due to drought stress was 

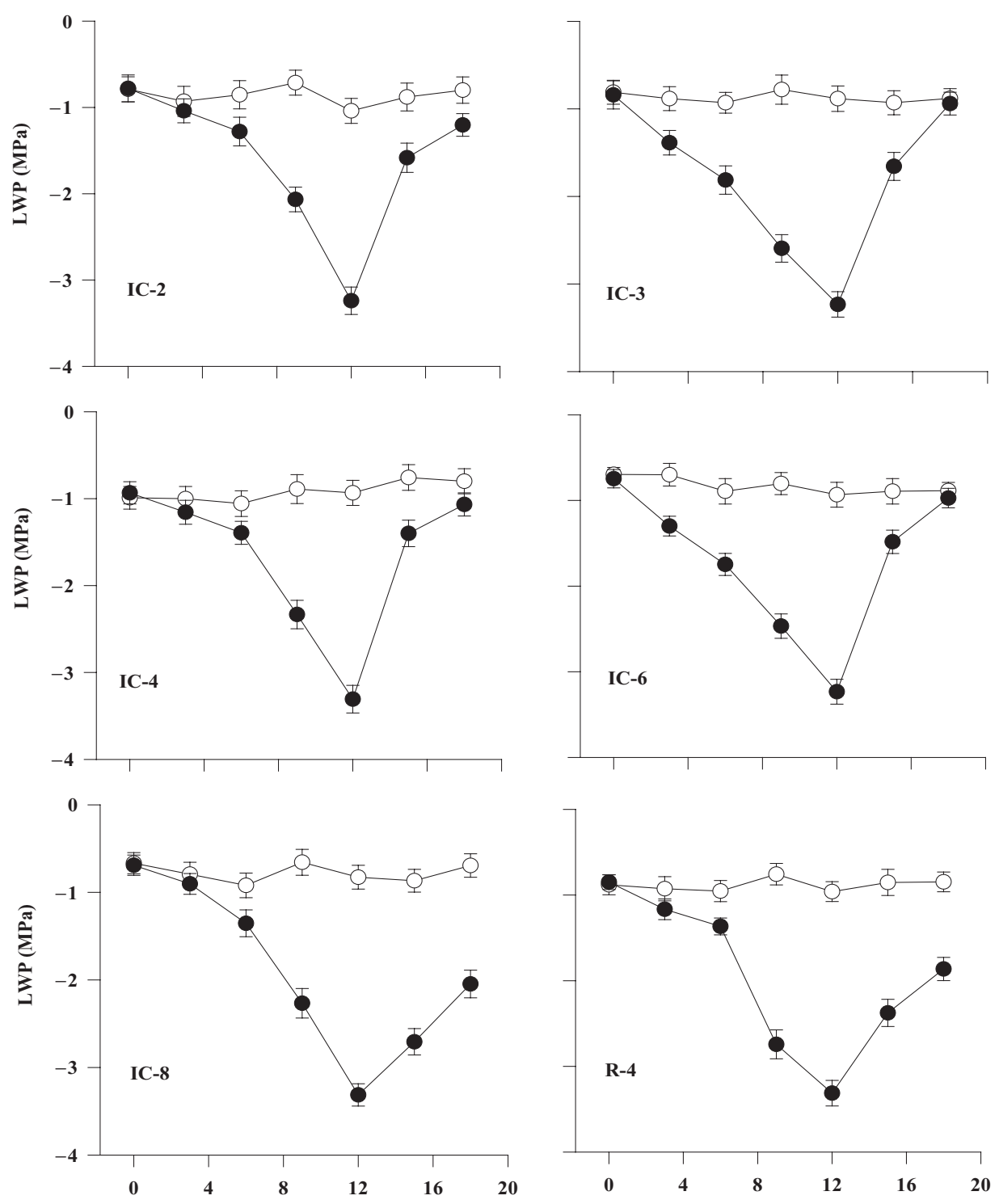

Days from start of treatment

Figure 1. Leaf water potential (LWP) of six Robusta coffee clones as affected by water stress and its recovery upon rewatering 12 days after soil drying (closed symbols represent water-stressed and open ones well-watered treatments). Bars represent standard error of means of each three observations.

considerably higher and more obvious on days 8 and 12 than on day 4 in IC- 6 and IC-8 (Figure 3).

All the clones except IC-6 and IC-8 showed a negative carbon balance with more negative value for clone R-4 at the end of the stress period on day 12 (Table 1). On the other hand, the rate of recovery in net $P_{\mathcal{N}}$ was considerably higher in IC-6, followed 

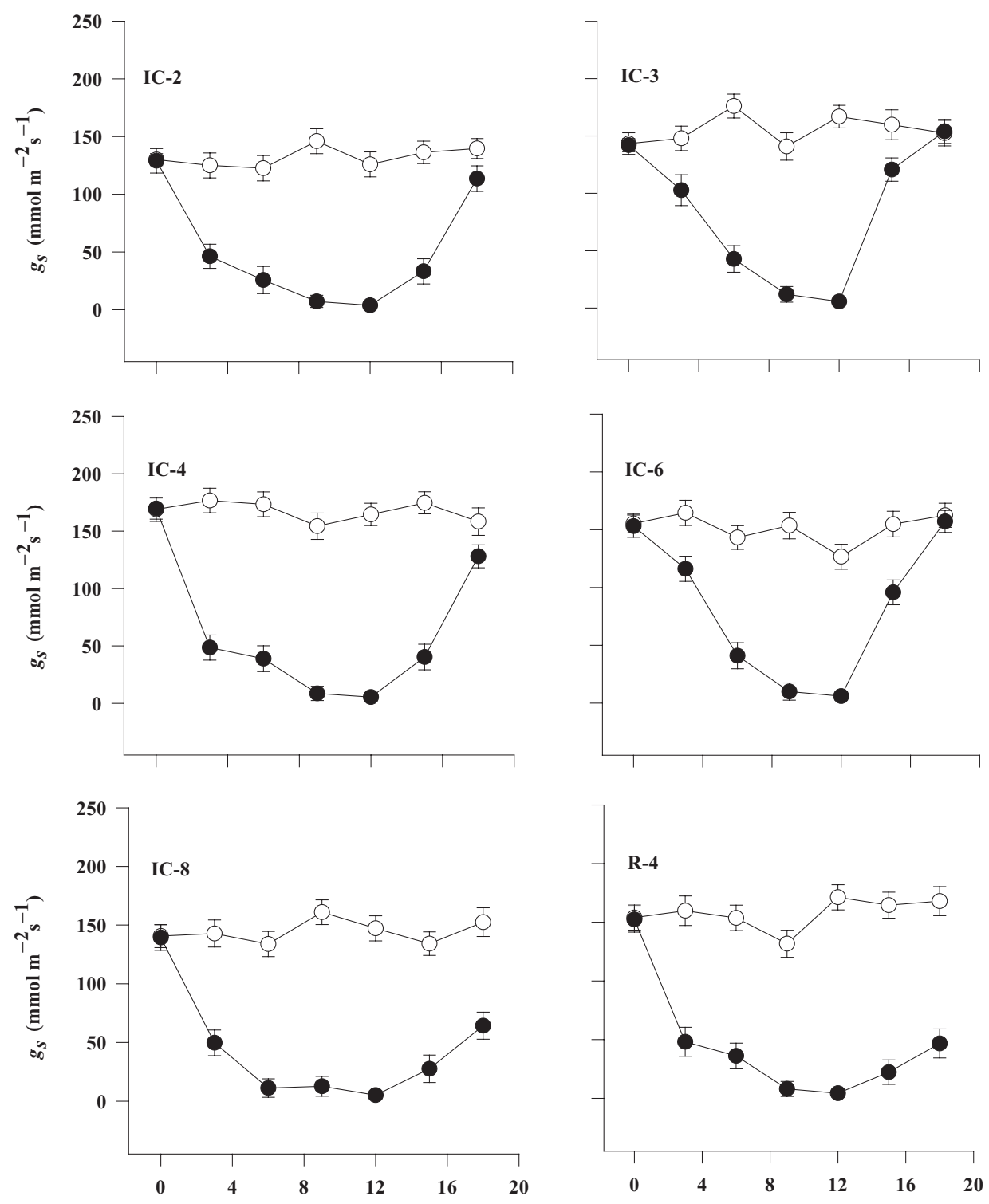

Days from start of treatment

Figure 2. Stomatal conductance $\left(g_{s}\right)$ of six Robusta coffee clones as affected by soil drying and rate of recovery upon rewatering 12 days after water deficit stress (open symbols represent well-watered control plants and closed symbols represent water-stressed ones). Bars represent standard error of means of each three observations.

by IC-3, than for IC-2, IC-4, IC-8 and R-4 just four days after rewatering. Eight days after the commencement of rewatering, $P_{\mathcal{N}}$ rate in $\mathrm{IC}-3$ and $\mathrm{IC}-6$ reached the level of the control plants, but it was still lower than that of the controls in IC-2, IC-4, IC-8 and R-4, with the lowest value being for clone R-4 (Figure 3). 

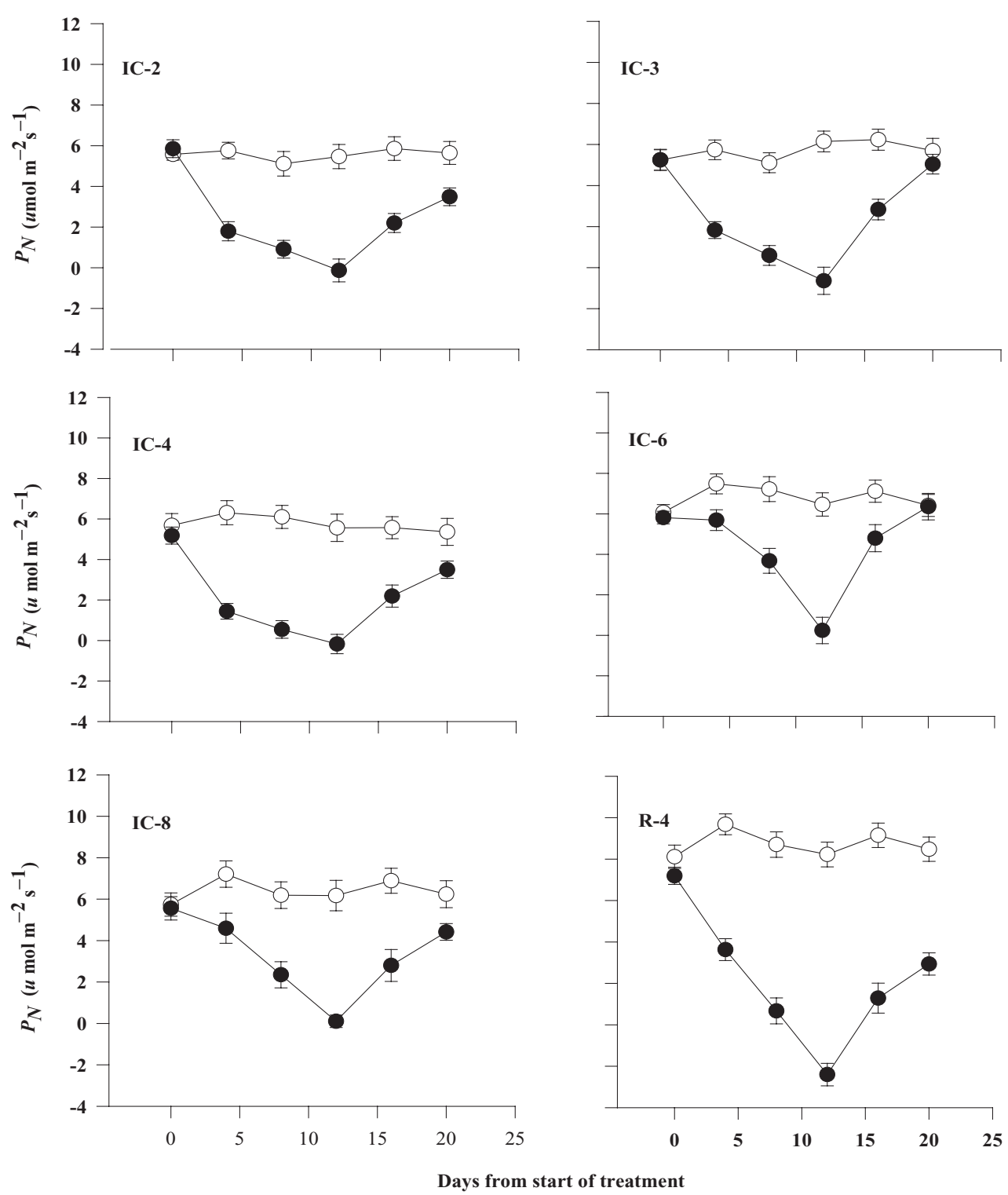

Figure 3. Rate of net photosynthesis $\left(P_{\mathcal{N}}\right)$ of six Robusta coffee clones as affected by soil drying and rewatering on day 12 when complete wilting symptoms were observed (open symbols represent well-watered and closed ones water-stressed treatments). Bars represent standard error of means of each three observations.

\section{Proline accumulation in leaves}

All coffee clones responded to soil drying by substantial increase in their LP concentration by as much as 14 folds compared with the controls. The control plots also exhibited variations in proline accumulation. Three days after withholding irrigation, the accumulation of LP was highest (over 14 folds) in IC-6, but it increased by only $84 \%$ in IC-4 and the remaining four clones exhibited 112 to $157 \%$ increase over 

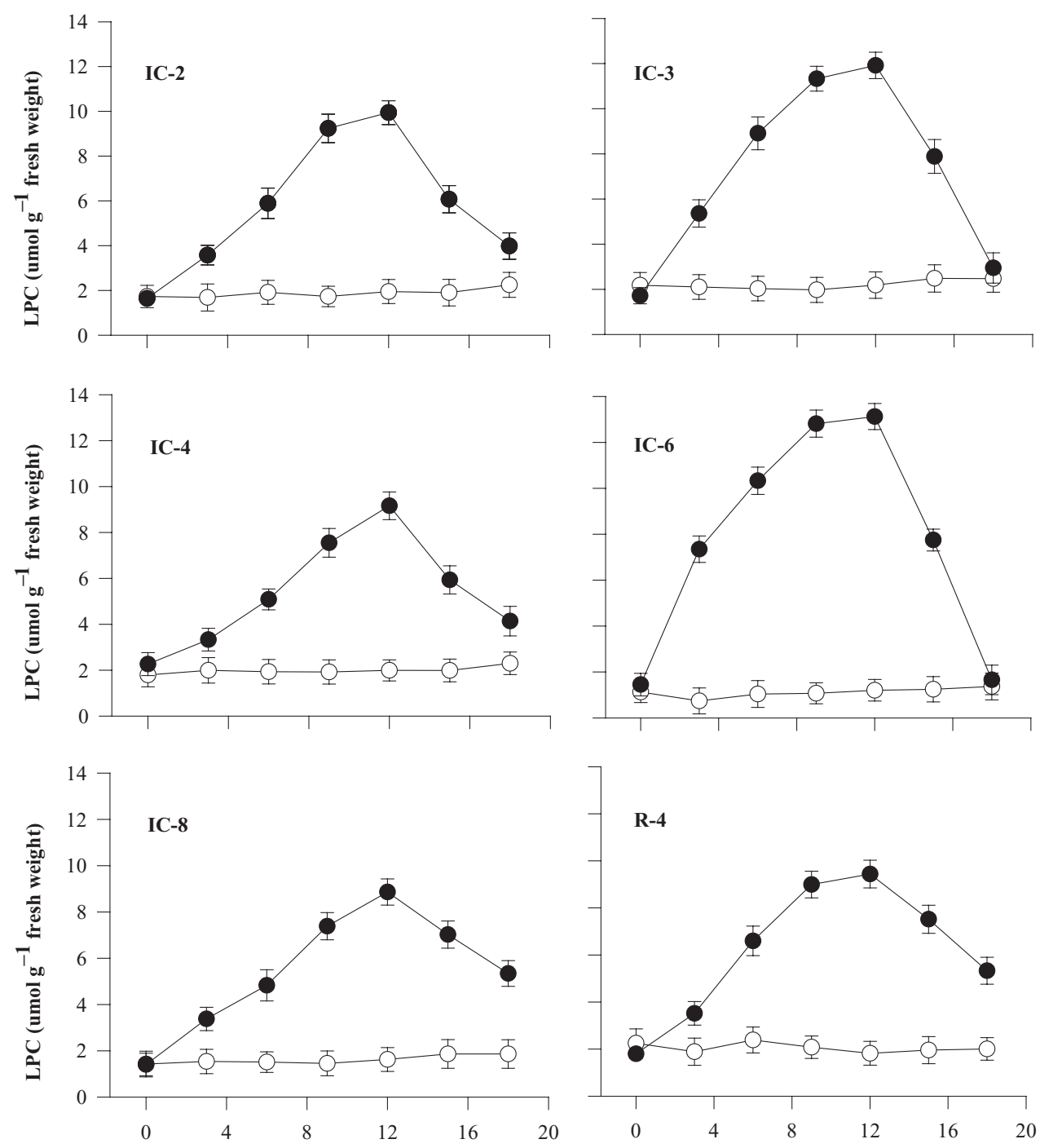

Days from start of treatment

Figure 4. Leaf proline concentration (LPC) of six Robusta coffee clones as affected by soil drying and rewatering on day 12 when complete wilting symptoms were observed (open symbols represent well-watered and closed ones water-stressed treatments). Bars represent standard error of means of each three observations.

their respective controls. The level of LP reached its peak in all the clones 12 days after withholding irrigation (Table 1), although there was only a slight increment from values measured on day 9 for IC-2, IC-3, IC- 6 and R-4 and it increased progressively in IC-4 and IC-8 (Figure 4). LP concentration of all the clones decreased when the plants were rewatered at the end of the soil drying cycle on day 12. However, the rate of its decline differed between the clones, as it dropped to the level exhibited by 


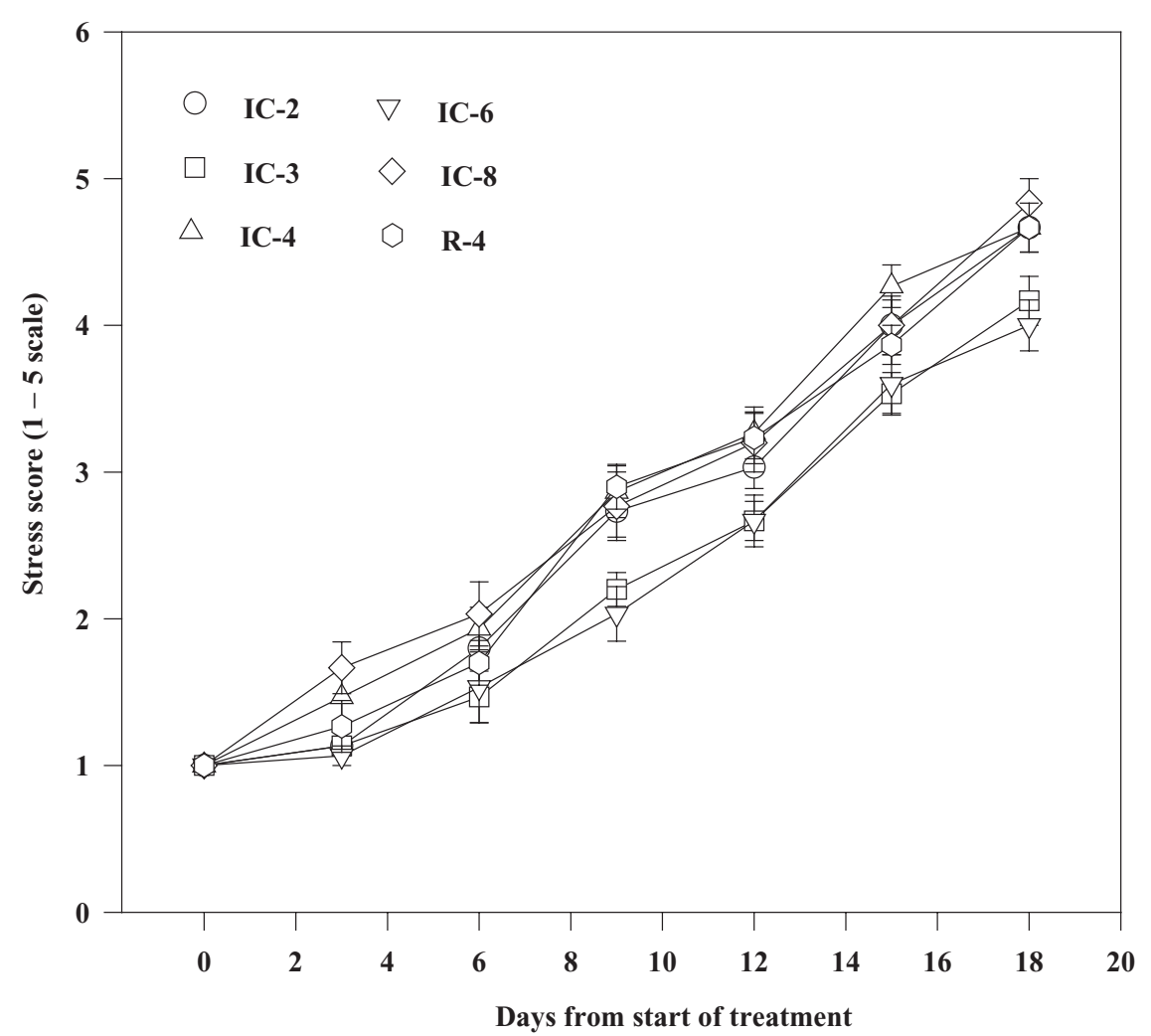

Figure 5. Sensitivity of Robusta coffee clones to soil drying as estimated by stress scores (visual rating of the extent of wilting or leaf folding and damage to leaves). Bars represent standard error of means of each three observations.

well-watered control plants in IC-3 and IC-6 but was still higher in stressed plants than in non-stressed controls, especially in IC-8 and R-4 (Figure 4).

\section{Leaf folding and rate of leaf fall}

The rate of leaf folding or extent of wilting was considerably higher for clones IC-8, IC-4, R-4 and IC-2 than for IC-3 and IC-6 during the stress period. Clones IC-8, R-4, IC-2 and IC-4 exhibited severe wilting symptom with necrosis or chlorosis lesions on leaves 15 days after withholding irrigation. The stressed plants of especially these clones progressively showed a permanent wilting symptom and severe leaf drying or scorching and leaf fall 18 days after the commencement of the soil drying treatment (Figure 5). Clone IC-6, followed by IC-3, also showed significantly lower stress score values than did the rest of the clones during the dry spells under field condition (Table 4). However, sensitivity of all the clones to drought was higher in the rain shelter than under field condition (Tables 2 and 4).

The proportion of plants which showed the first wilting symptom (partial leaf folding) was higher (33\%) for IC-4 and IC-8 compared with IC-2, IC-3, IC-6 and 
Table 2. Sensitivity of Robusta coffee clones to soil drying as estimated by stress score values (SSV), rate of leaf fall (RLF), loss of total leaf area (LTLA) and total dry matter yield (LTDMY) and percentage of plants recovering (PPR) upon rewatering on day 21 after soil drying.

\begin{tabular}{lcllcl}
\hline Clone & SSV $(1-5$ scale $)$ & RLF $(\%)$ & LTLA $(\%)$ & LTDMY $(\%)$ & PPR (\%) \\
\hline IC-2 & $4.60 \mathrm{ab}$ & $78.73 \mathrm{~b}$ & $67.03 \mathrm{ab}$ & $51.94 \mathrm{c}$ & $60.0 \mathrm{c}$ \\
IC-3 & $4.00 \mathrm{bc}$ & $51.52 \mathrm{~d}$ & $49.01 \mathrm{~d}$ & $39.66 \mathrm{~d}$ & $86.5 \mathrm{a}$ \\
IC-4 & $4.60 \mathrm{ab}$ & $82.13 \mathrm{ab}$ & $62.79 \mathrm{bc}$ & $67.78 \mathrm{~b}$ & $71.5 \mathrm{~b}$ \\
IC-6 & $3.80 \mathrm{c}$ & $65.05 \mathrm{c}$ & $57.79 \mathrm{c}$ & $36.97 \mathrm{~d}$ & $86.5 \mathrm{a}$ \\
IC-8 & $4.80 \mathrm{a}$ & $90.89 \mathrm{a}$ & $74.35 \mathrm{a}$ & $71.49 \mathrm{a}$ & $51.5 \mathrm{c}$ \\
R-4 & $4.60 \mathrm{ab}$ & $86.95 \mathrm{ab}$ & $68.85 \mathrm{ab}$ & $72.38 \mathrm{a}$ & $36.5 \mathrm{~d}$ \\
\hline
\end{tabular}

Figures followed by the same letters within a column are not significantly different at $p=0.05$.

Table 3. Growth and total dry matter yield (TDMY) of Robusta coffee clones under well-watered (WW) and drought-stressed (DS) conditions at seedling stage after 21 days of soil drying.

\begin{tabular}{llllclc}
\hline Clone & Watering & PHt. $(\mathrm{cm})$ & Girth $(\mathrm{mm})$ & TLA $\left(\mathrm{cm}^{2}\right)$ & TDMY $(\mathrm{g})$ & Root to shoot ratio \\
\hline IC-2 & WW & $60.03 \mathrm{c}$ & $10.97 \mathrm{bcdef}$ & $1944.3 \mathrm{ab}$ & $48.90 \mathrm{~b}$ & $0.367 \mathrm{f}$ \\
& DS & $53.70 \mathrm{e}$ & $10.03 \mathrm{ef}$ & $641.3 \mathrm{c}$ & $24.47 \mathrm{e}$ & $0.410 \mathrm{de}$ \\
IC-3 & WW & $63.03 \mathrm{ab}$ & $11.77 \mathrm{bcd}$ & $1791.3 \mathrm{~b}$ & $50.50 \mathrm{~b}$ & $0.437 \mathrm{c}$ \\
& DS & $58.93 \mathrm{c}$ & $10.87 \mathrm{cdef}$ & $913.3 \mathrm{c}$ & $30.63 \mathrm{~d}$ & $0.523 \mathrm{a}$ \\
IC-4 & WW & $56.53 \mathrm{~d}$ & $11.47 \mathrm{bcde}$ & $1784.3 \mathrm{~b}$ & $54.23 \mathrm{a}$ & $0.417 \mathrm{cde}$ \\
& DS & $49.33 \mathrm{f}$ & $9.63 \mathrm{f}$ & $664.0 \mathrm{c}$ & $18.00 \mathrm{f}$ & $0.397 \mathrm{e}$ \\
IC-6 & WW & $65.00 \mathrm{a}$ & $13.43 \mathrm{a}$ & $2426.0 \mathrm{a}$ & $53.33 \mathrm{a}$ & $0.473 \mathrm{~b}$ \\
& DS & $60.90 \mathrm{bc}$ & $12.53 \mathrm{ab}$ & $1024.0 \mathrm{c}$ & $33.30 \mathrm{~d}$ & $0.490 \mathrm{~b}$ \\
IC-8 & WW & $60.00 \mathrm{c}$ & $12.40 \mathrm{abc}$ & $2277.3 \mathrm{ab}$ & $55.87 \mathrm{a}$ & $0.467 \mathrm{~b}$ \\
& DS & $53.23 \mathrm{e}$ & $10.80 \mathrm{def}$ & $584.0 \mathrm{c}$ & $15.97 \mathrm{f}$ & $0.397 \mathrm{e}$ \\
R-4 & WW & $55.33 \mathrm{de}$ & $11.10 \mathrm{bcdef}$ & $1720.0 \mathrm{~b}$ & $38.10 \mathrm{c}$ & $0.433 \mathrm{~cd}$ \\
& DS & $49.67 \mathrm{f}$ & $9.60 \mathrm{f}$ & $535.7 \mathrm{c}$ & $10.80 \mathrm{~g}$ & $0.410 \mathrm{de}$ \\
\hline
\end{tabular}

Figures followed by the same letters within a column are not significantly different at $p=0.05$. PHt. = plant height; TLA $=$ total leaf area per plant.

R-4, 13 to $23 \%$ of plants of which exhibited the symptom three days after soil drying. On the other hand, 53 to $60 \%$ of the plants of all the clones except IC-3 and IC-6 showed obvious wilting symptoms six days after the stress treatment. Mean percentage of plants wilted increased to $90 \%$ for IC-2 and IC-4 and to $87 \%$ for IC-8 and R-4, but it was 70-77\% for IC-3 and IC- 6 after nine days of withholding water. Three days later, about $97 \%$ of the plants of IC-2, IC-4, IC-8 and R-4 wilted completely, while about $87 \%$ of those of IC-3 and IC- 6 showed such a complete wilting symptom (Figure 6, Table 1). As a result, rate of leaf fall $(51.52-65.05 \%)$ and loss of total leaf area (49.01-57.79\%) were significantly lower, but percentage of plants recovered upon rewatering after 21 days of drought stress was considerably higher $(86.5 \%)$ for IC-6 and IC-3 than for IC-2, IC-4, IC-8 and R-4, for which the respective values ranged from 78.73 to $90.89 \%, 62.79$ to $74.35 \%$ and 36.5 to $71.5 \%$ (Table 2). 
Table 4. Growth and sensitivity of Robusta coffee clones to dry spells as estimated by stress score values (SSV: 1-5 scale) under field rain-fed condition.

\begin{tabular}{lllll}
\hline Clone & PHt. $(\mathrm{cm})$ & Girth $(\mathrm{mm})$ & CD $(\mathrm{cm})$ & SSV \\
\hline IC-2 & $158.33 \mathrm{bc}$ & $28.80 \mathrm{c}$ & $116.61 \mathrm{bc}$ & $2.40 \mathrm{ab}$ \\
IC-3 & $160.90 \mathrm{ab}$ & $32.40 \mathrm{~b}$ & $120.51 \mathrm{ab}$ & $1.80 \mathrm{bc}$ \\
IC-4 & $155.17 \mathrm{~d}$ & $26.97 \mathrm{~d}$ & $111.57 \mathrm{~d}$ & $2.80 \mathrm{a}$ \\
IC-6 & $161.80 \mathrm{a}$ & $34.40 \mathrm{a}$ & $123.99 \mathrm{a}$ & $1.73 \mathrm{c}$ \\
IC-8 & $156.40 \mathrm{~cd}$ & $27.83 \mathrm{~cd}$ & $112.77 \mathrm{~cd}$ & $2.80 \mathrm{a}$ \\
R-4 & $158.17 \mathrm{bc}$ & $28.63 \mathrm{c}$ & $115.17 \mathrm{~cd}$ & $2.40 \mathrm{ab}$ \\
\hline
\end{tabular}

Figures followed by the same letters within a column are not significantly different at $p=0.05$.

PHt. = plant height $\mathrm{CD}=$ canopy diameter.

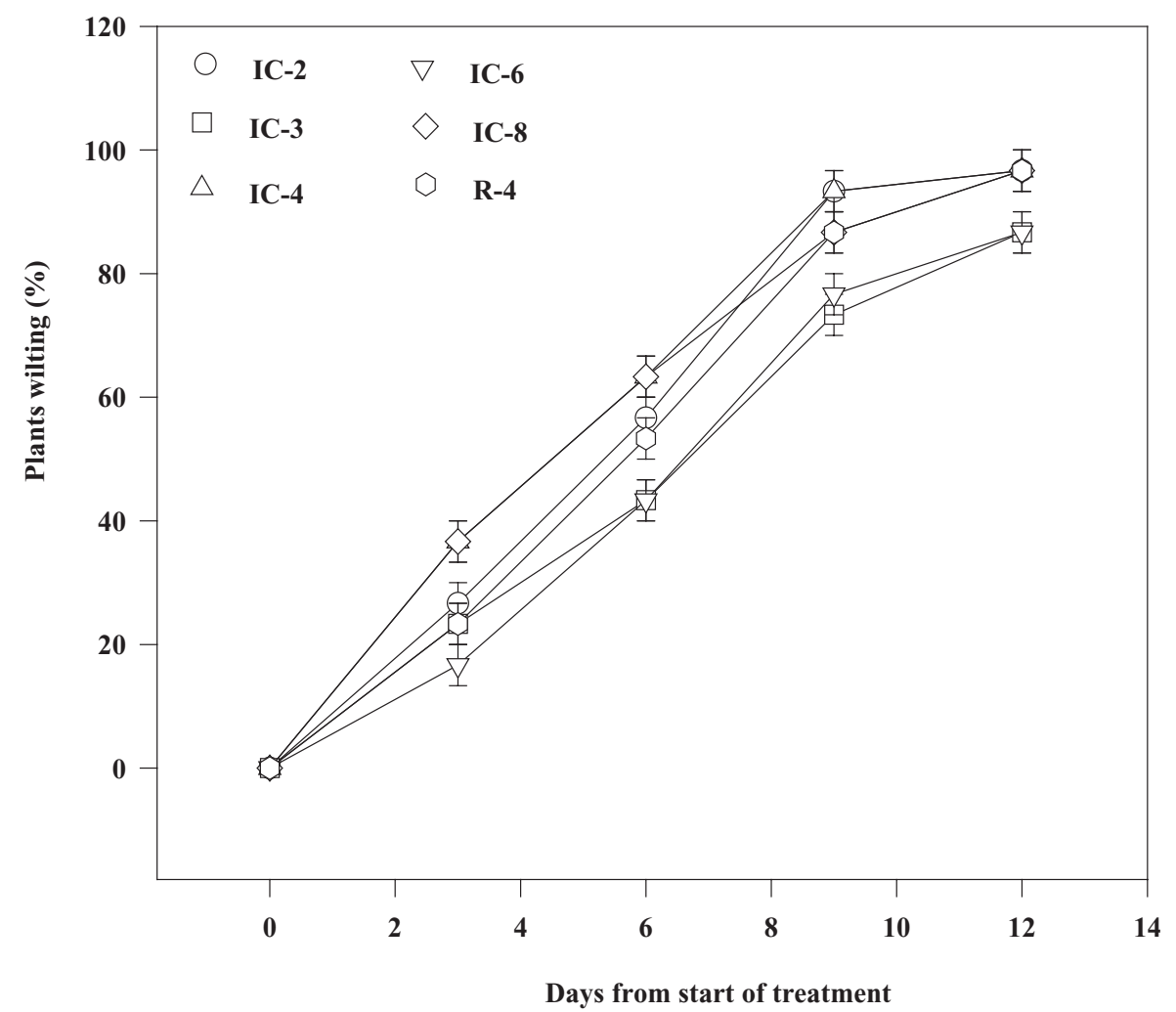

Figure 6. Sensitivity of Robusta coffee clones to soil drying as estimated by proportion of plants showing complete wilting symptoms. Bars represent standard error of means of each three observations.

Vegetative growth and total dry matter yield

Plant height, girth, total leaf area, total dry matter yield and root to shoot ratio were significantly affected by drought stress. There were also significant differences among the clones for these parameters. It was observed that clone IC-6, followed by IC-3, exhibited the highest plant height under well-watered condition. Among the 
drought-stressed plots, clones IC-6 and IC-3 had still higher plant height, total dry matter yield and root to shoot ratio than did the other clones. The highest girth and the total leaf area were also observed for clone IC-6 under both well-watered and drought-stressed conditions (Table 3).

Similarly, as observed in the rain shelter, plant height, girth and canopy diameter were significantly higher, but sensitivity to dry spells as estimated by visual rating for the rate of stress development was significantly lower for clone IC-6, followed by IC-3, than for IC-2, IC-4, IC-8 and R-4 under rain-fed field condition (Table 4).

\section{DISCUSSION}

\section{Leaf gas exchange}

Leaf water potential, $g_{s}$ and $P_{\mathcal{N}}$ declined substantially with prolonged period of soil drying. Although the rate of decline varied with clone, these parameters had the lowest values for all the clones at the end of the stress period on day 12 (Figures 1-3, Table 1). These results were quite in agreement with the findings of Lima et al. (2002) on pot-grown plants of both drought-sensitive and drought-tolerant Robusta coffee clones, where LWP has decreased to -3.0 MPa and led to complete suppression of $g_{s}$ and net $P_{\mathcal{N}}$ six days after withholding irrigation. Similar results have also been reported for Arabica coffee, where $g_{s}$ and the rate of net $P_{\mathcal{N}}$ began to decline as LWP fell below $-2.0 \mathrm{MPa}$ and became almost zero when LWP decreased to -3.0 MPa after 11 days of water stress (Kanechi et al., 1988). As observed in the present study, especially for coffee clones IC-3 and IC-6, it has been reported that drought stress usually causes significant decreases in both $P_{\mathcal{N}}$ rate and $g_{s}$ (Krieg, 1983) as a consequence of considerable reduction in LWP of plants (Tardieu and Davies, 1992). Such decreases in $P_{\mathcal{N}}$ and $g_{s}$ with reductions in plant water status have been observed in drought-stressed plants of banana, peanut and rice (Adam and Barakbah, 1990), tomato (Ismail and Dalia, 1995), evergreen sclerophylls (Rhizopoulou et al., 1991), drought-tolerant angiosperms (Loewenstein and Pallardy, 1998a, b), both Arabica (Tesfaye et al., 2008) and Robusta coffees (Tesfaye et al., 2013a), grapevines (de Souza et al., 2003, dos Santos et al., 2003) and common bean (Wakrim et al., 2005).

Consistent with the results of the present study, the findings of Ismail et al. (1994) on two durian clones have also shown that the rate of decline in LWP, $g_{s}$ and $P_{\mathcal{N}}$ during drought stress period greatly varies with species or genotype (whether drought-sensitive or tolerant).

On the other hand, unlike LWP, the rate of decline in $g_{s}$ was faster during the early stages of the stress period until day 3 and then it gradually decreased for clones IC-2, IC-4, IC-8 and R-4. But clones IC-3 and IC-6 showed similar trend and relatively constant rate of decline in both LWP and $g_{s}$ during the stress period. Besides, the rate of decrease in net $P_{\mathcal{N}}$ also followed the same trend as observed for $g_{s}$ in IC-2, IC-3 and IC-4, and for $g_{s}$ and LWP in IC-6. In line with this, the decline in net $P_{\mathcal{N}}$ of drought-stressed plants has been mostly attributed to the reduced $g_{s}$ (Ismail and Dalia, 1995; Pugnaire et al., 1999), as it has been reported that soil moisture depletion normally decreases the rate of net $P_{\mathcal{N}}$ due to its adverse effect on $g_{s}$ of $\mathrm{C}_{4}$ plants, such 
as maize (Kang et al., 1998; Nagy et al., 1993), durian clones (Ismail et al., 1994) and drought-sensitive species like some woody angiosperms (Loewenstein and Pallardy, $1998 \mathrm{a}, \mathrm{b})$.

Stomatal closure in response to soil drying has also been reported for pepper (Awad, 2001), grapevine (Stoll et al., 2000) and tomatoes (Hassan et al., 2003; Mingo et al., 2004). In most cases, decline in turgor pressure and, thus $g_{s}$ and $P_{\mathcal{N}}$ of plants subjected to a drying soil, is attributed to decrease in plant water status, indicating stomatal regulation by hydraulic signals (Auge and Moore, 2002; Tardieu and Davies, 1993), especially in drought-tolerant or less sensitive species or genotypes (Gaff and Loveys, 1992; Loewenstein and Pallardy, 1998a, b; Volkmar and Woodbury, 1995). In contrast, as discussed earlier, it has been observed that $g_{s}$ was affected by soil drying without a significant reduction in leaf water status in apple (Gowing et al., 1990), common bean (Trejo and Davies, 1991), soybean (Liu et al., 2003), tomatoes (Hassan et al., 2003; Mingo et al., 2004; Zegbe-Dominguez et al., 2003) and Arabica coffee seedlings (Tesfaye et al., 2008). As observed in this study as well as in some earlier studies, such a stomatal response to water stress in advance of a measurable change in LWP could occur during the early stages of stress development and may result in the reduced rate of $P_{\mathcal{N}}$ in drought-sensitive genotypes (Loewenstein and Pallardy, 1998a, b; Saliendra et al., 1995), probably as a result of chemical signals produced by the roots and transported in the xylem sap to the leaves of drought-stressed plants (Bacon et al., 1998; Davies et al., 1994; Tardieu and Davies, 1992; Thompson et al., 1997). Roots in drying soils produce a drought stress signaling biochemical known as abscissic acid (ABA). This root-sourced plant hormone is transported to the shoot system, particularly to the leaves, and causes stomatal closure (reduction in stomatal opening), and thus reduces rate of loss of water from the plant system through transpiration. In line with this, it has been reported that increase in root-sourced ABA concentration (Davies et al., 1994; Naqvi, 1999; Stoll et al., 2000; Tardieu et al., 1991) and/or changes in $\mathrm{pH}$ of the xylem sap (Bacon et al., 1998; Gollan et al., 1992; Kirda et al., 2004; Thompson et al., 1997) may be responsible for triggering stomatal closure in plants subjected to drought stress.

On the other hand, $P_{\mathcal{N}}$ rate of coffee clones IC-2, IC-3, IC-4 and R-4 declined to negative values while plants of clones IC-6 and IC-8 experienced a positive carbon balance under severe water stress reflected by a similar low LWP and $g_{s}$ at the end of the soil drying period. In agreement with these results, Adam and Barakbah (1990) reported that banana plants exhibited a slow decline in $P_{\mathcal{N}}$ rate and maintained a positive carbon balance despite complete stomatal closure, but rice plants with partial stomatal opening had a negative value of $P_{\mathcal{N}}$ during a severe water stress period, indicating greater sensitivity of rice to drought compared with banana plants. Ismail et al. (1994) have also observed a decline in $P_{\mathcal{N}}$ rate of a drought-sensitive durian clone to a negative value probably due to a higher stomatal resistance under severe water stress and maintenance of photosynthetic activity at the same degree of stress, although at a slower rate in plants of a drought-tolerant clone. It has been suggested that such differential $P_{\mathcal{N}}$ and $g_{s}$ responses of genotypes to drought stress may be associated with factors controlling $P_{\mathcal{N}}$ at both stomatal and non-stomatal levels (probably at mesophyll 
level, the soft parenchyma tissue containing chlorophyll between the epidermal layers of the leaf, which may also be involved in gas exchange in the plant system, especially photosynthetic $\mathrm{CO}_{2}$ fixation by chlorophyll in leaves) (Nagy et al., 1993; Pugnaire et al., 1999; Volkmar and Woodbury, 1995). It has been reported that net $P_{\mathcal{N}}$ in coffee was more related to mesophyll conductance than to total $g_{s}$ (Barros et al., 1997), although it has been observed that the $P_{\mathcal{N}}$ rate in coffee leaves increased with increasing $g_{s}$ up to about $120 \mathrm{mmol} \mathrm{m}^{-2} \mathrm{~s}^{-1}$ (Fanjul et al., 1985). Besides, the rate of decrease in $P_{\mathcal{N}}$ rate and the mechanism involved in its depression may vary with the severity of stress. As it has been reported by Lawlor (1995) and Lima et al., (2002), the rate of $P_{\mathcal{N}}$ decreases due to stomatal closure under moderate water deficit conditions, but biochemical constraints, mainly photoinhibition and photo-oxidative damages to the photosynthetic apparatus because of absorption of excess excitation energy and formation of active oxygen species (Navari-Izzo and Rascio, 1999; Smirnoff, 1995), may limit the photosynthetic $\mathrm{CO}_{2}$ fixation more directly as the stress progresses.

Besides, the rate of recovery in LWP, $g_{s}$ and $P_{\mathcal{N}}$ after rewatering also varied among coffee clones, and it was rapid in IC-2, IC-3, IC-4 and IC-6 compared with IC-8 and R-4. Similar results have been reported by Barros et al. (1997), where application of irrigation increased LWP of water-stressed coffee plants, and thus irrigated plants were sustained under a more favourable water status, while the non-irrigated ones suffered a greater water stress as indicated by the reduced LWP during the peak dry season. Genetic variation in the rate of recovery in LWP and an increase in plant water status during relief from drought have also been reported for different evergreen sclerophylls (Rhizopoulou et al., 1991). Hence, differences between coffee clones for rate of recovery in $g_{s}$ after rewatering could be associated with variations in the rate of maintenance of LWP, and thus turgidity (Rhizopoulou et al., 1991; Volkmar and Woodbury, 1995). It is also possible that chemical signals, probably accumulated during the stress period, might have been diluted in the transpiration stream by the increased soil and plant water status, thus causing signal concentration to be too low to induce stomatal closure in those coffee clones that exhibited complete recovery in $g_{s}$ six days after rewatering. Increases in the level of growth substances of gibberellins type by increased plant water status (Naqvi, 1999) might have also overcome the inhibitory effects of the high levels of ABA in water-stressed plants, and hence might have improved $g_{s}$ during the rewatering phase, although the concentration of these substances has not been measured in the course of the present study. On the other hand, differences between coffee clones for the rate of recovery in net $P_{\mathcal{N}}$ could be associated with variations in the rate of increase in $g_{s}$ probably as a consequence of increased LWP, since the rate of $P_{\mathcal{N}}, g_{s}$ and LWP followed a similar trend of increase particularly in clones IC-2, IC-3, IC-4 and IC-6 just after rewatering. These results were quite in agreement with the findings of Nagy et al. (1993), who suggested that stomatal limitation plays the main role in regulating net $P_{\mathcal{N}}$ and transpiration during a prolonged drought and after rewatering in maize plants.

The rate of increase in $g_{s}$ after rewatering was, however, much smaller than the rate of increase in LWP and $P_{\mathcal{N}}$ in IC-8 and R-4. Increase in $P_{\mathcal{N}}$ despite significantly lower $g_{s}$ in these clones might be attributed to increased non-stomatal (mesophyll) conductance, 
probably because of increase in LWP. Consistent with this, Barros et al. (1997) have reported that net $P_{\mathcal{N}}$ in coffee leaves was more related to mesophyll conductance than to $g_{s}$. It is also possible that differential responses of coffee clones to photoinhibitory and photo-oxidative damages during drought (Karpinski et al., 1999; Lawlor, 1995; Smirnoff, 1995) and variations in the rate of recovery of the entire photosynthetic apparatus upon rewatering (Lima et al., 2002; Navari-Izzo and Rascio, 1999) might have accounted for the observed differences among the clones for the rate of recovery of net $P_{\mathcal{N}}$ in the present study. In line with this, it has been reported that attributes of tolerance in a drought-tolerant Robusta coffee clone were linked to less oxidative damages (more protection against photo-oxidation of the photosynthetic apparatus) because of relatively greater increase in the capacity of its antioxidant system compared with that of the drought-sensitive clone (Lima et al., 2002). Such differences between genotypes for oxidative stress tolerance under water deficit condition and rate of maintenance of photosynthetic apparatus and net $P_{\mathcal{N}}$ have also been reported for different resurrection plants and angiosperms (Navari-Izzo and Rascio, 1999).

\section{Proline accumulation in leaves}

Concentration of LP increased as a result of soil drying, and the rate of its increase with increasing time of stress differed between the clones. There was also obvious difference between the clones for proline accumulation even under well-watered condition (Figure 4). Consistent with the results of the present study, Maestri et al. (1995) have observed differences among coffee cultivars for the concentration of LP under both control and drought-stressed conditions, but stressed plants accumulated substantially higher level than the non-stressed ones. In his review article, Heuer (1999) has also indicated that drought stress imposed by withholding irrigation induced proline accumulation in the leaves of sorghum, wheat, barley, maize, cotton, sunflower, tomato, sugar beets, teff and coffee. Similarly, the accumulation of LP in plants grown under drought stress conditions has also been reported for durian (Ismail et al., 1994) and tomato (Hassan et al., 2003), as well as for different evergreen sclerophyll species (Rhizopoulou et al., 1991). In line with this, several workers have correlated drought tolerance with increase in LP concentration during genotype screening, as proline is believed to be one of the most important compatible solutes that play a vital role in osmotic adjustment in crops subjected to water deficit and salinity stresses (Bates et al., 1973; Hassan et al., 2003; Pugnaire et al., 1999). Hence, the rate of accumulation of proline has been regarded as a tolerance mechanism and adaptation of genotypes to drought stress through osmoregulation in a number of crops, including sorghum (Volkmar and Woodbury, 1995), tomato (Hassan et al., 2003), durian (Ismail et al., 1994), wheat (Heuer, 1999; Volkmar and Woodbury, 1995) and banana (Siamak et al., 2012). Ismail et al. (1994) and Siamak et al. (2012) have also reported that the concentration of LP was significantly higher in a drought-tolerant durian and banana clones, respectively, than in the drought-sensitive ones. Similarly, review of relevant literature by Heuer (1999) has indicated that free proline production and accumulation was correlated with varietal differences in osmoregulation and thus stress tolerance in 
alfalfa, safflower, Indian mustard, rice and wheat cultivars. A good correlation between the concentrations of proline and osmotic potential, osmotic adjustment at zero turgor and plant water potential has also been observed with varietal differences for these parameters in both Arabica and Robusta coffees (Maestri et al., 1995).

In the present study, clones IC-6 and IC-3 exhibited a more rapid and much higher accumulation of LP compared with other coffee clones just following the commencement of soil drying and throughout the water stress period. Increase in proline accumulation in leaves of drought-stressed coffee plants was associated with decrease in LWP, and thus a mechanism of osmotic adjustment in cells or maintenance of turgidity to overcome the stress. Therefore, differences between coffee clones for the level and rate of proline accumulation with increasing time of water stress might be associated with variations for osmotic adjustment and drought tolerance. In line with this, it has been suggested that the accumulation of proline could be used as a single parameter to measure physiological dryness in plants (Bates et al., 1973), and thus the rapidity of its accumulation in leaf tissue following the onset of dehydration could be regarded as one of the indicatives of osmoregulation in drought-tolerant genotypes (Ismail et al., 1994; Siamak et al., 2012).

Coffee clones also showed variations in the rate of decrease in LP concentration as a result of rewatering. The concentration of proline declined sharply and reached a level similar to that of the non-stressed control plants for IC-6 and IC-3, while it was still higher in drought-stressed plants than in the controls, especially for clones IC-8 and R-4 even six days after rewatering (Figure 4). In agreement with these results, Heuer (1999) has reviewed that the level of drought stress-induced proline accumulation in the leaves of sorghum plants decreased by rewatering, but remained relatively high when compared with non-stressed controls. On the other hand, the concentration of proline in drought-stressed wheat and cotton plants dropped to the control level within two days after rewatering (Heuer, 1999). In general, lower rate of proline accumulation in irrigated control plants and drastic reduction of its concentration with rewatering after stress might be associated with its oxidation, as plants can convert free proline into glutamic acid through series of biochemical reactions under non-stress conditions (Heuer, 1999). It is also possible that the accumulated proline during the stress period might have been used as a source of respiratory energy and nitrogen $(\mathrm{N})$ during the rewatering phase (Heuer, 1999).

\section{Leaffolding and rate of leaffall}

In general, extent of wilting (mean stress rating) (Figure 5), mean percentage of wilted plants (Figure 6) and rate of leaf fall (Table 2) were considerably higher for IC2, IC-4, IC-8 and R-4 than for IC-3 and IC-6 during the water stress period. Lower rate of stress development (less wilting symptom and gradual leaf rolling, cupping or folding) as a result of maintenance of turgor has been used as an important criterion during screening of genotypes of mungbean (Vigna radiate) (Rosario et al., 1992), soybean (Carter and Rufty, 1992) and rice (Lilley and Fukai, 1994; Price et al., 1992) for drought tolerance. Besides, maintenance of turgor and stay-green under water stress conditions 
has also been used as one of the traits to select corn varieties for drought tolerance (Kitbamroong and Chantachume, 1992). As observed in the present study, differences among coffee clones for the rate of stress development, expressed by the extent of wilting and damage on leaves, and the corresponding visual stress score value might be attributed to variations in osmotic adjustment as a result of proline accumulation in leaves. In line with this, clones IC-3 and IC-6, which exhibited lower mean stress score (lower rate of stress development), rate of leaf fall and percentage of wilting plants, and thus maintained higher total leaf area and leaf turgidity, had considerably higher LP accumulation (Figure 4) during the drought stress period. Maintenance of turgor by osmotic adjustment is believed to be one of the most important mechanisms of adaptation (Maestri et al., 1995; Meinzer et al., 1992; Pugnaire et al., 1999), allowing plant growth (Heuer, 1999) and reducing the rate of leaf senescence (stay-green trait or slower-than-normal wilting pattern) by increasing both avoidance and tolerance of dehydration under drought stress conditions (Carter and Rufty, 1992; Joshi, 1999; Siamak et al., 2012).

\section{Growth and dry matter yield}

On the other hand, coffee clones with lower values of stress score and rate of leaf fall exhibited higher rate of recovery upon rewatering, higher vegetative growth (plant height, girth and total leaf area), total dry matter yield and root to shoot ratio and lower level of loss in total leaf area and total dry matter yield than those clones that showed sever wilting and leaf fall. The same trend was also observed under field condition for some vegetative growth parameters (plant height, girth and canopy diameter) and stress score values. Consistent with the results of the present study, it has been reported that leaf scorching scores due to drought stress were inversely correlated with vegetative growth parameters in different Arabica (Tesfaye et al., 2013b) and Robusta (Anim-Kwapong et al., 2011) coffee genotypes and can be used as a criteria to screen drought-tolerant materials.

\section{CONCLUSIONS}

The rate of stress development, decline in LWP, $g_{s}$ and $P_{\mathcal{N}}$ and accumulation of proline during water stress period and changes in these parameters after rewatering greatly differed among coffee clones. The clones also varied with respect to vegetative growth, dry matter yield and root to shoot ratio. The rate of stress development in clones IC-6 and IC-3 was generally lower than its values for the other clones. These clones also exhibited quite a better performance in almost all the parameters considered in this study and seemed to be less sensitive to drought stress than did IC-2, IC-4, IC-8 and R-4 under both controlled and field conditions. Drought tolerance attributes in these clones could be linked to a more effective osmotic adjustment due to more rapid accumulation of proline in their leaves. Besides, some morphological traits, mainly increased root to shoot ratio, might have played a role in the response of these clones to soil drying. Therefore, it appears that both physiological and biochemical as well as morphological parameters are equally important and need due consideration during 
screening crop genotypes for drought tolerance. However, further molecular studies, detailed biochemical, physiological and morphological investigations and observations under diverse field conditions may be required to come up with more conclusive recommendations.

Acknowledgements. The authors wish to acknowledge the Ministry of Higher Education, Malaysia, "Fundamental Research Grant Scheme (FRGS)" for the financial support.

\section{REFERENCES}

Abernethy, G. A. and McManus, M. T. (1998). Biochemical responses to an imposed water deficit in mature leaf tissue of Festuca arundinacea. Environmental and Experimental Botany 40:17-28.

Adam, F. and Barakbah, S. S. (1990). Response to water stress in banana, peanut and rice: a comparative study. Transactions of Malaysian Society of Plant Physiology 1(1990): 99-104.

Anim-Kwapong, E., Anim-Kwapong, G. J. and Adomako, B. (2011). Variation and association among characters genetically related to yield and yield stability in Coffea canephora genotypes. Fournal of Plant Breeding and Crop Science 3(12): $311-320$.

Auge, R. M. and Moore, J. L. (2002). Stomatal response to non-hydraulic root-to-shoot communication of partial soil drying in relation to foliar dehydration tolerance. Environmental and Experimental Botany 47:217-229.

Awad, M. H. (2001. Effect of Water Deficit on Growth and Leaf Gas Exchange of Pepper Plants (Capsicum annuum). PhD thesis, Universiti Putra Malaysia, Malaysia.

Bacon, M. A., Wilkinson, S. and Davies, W. J. (1998). PH-regulated leaf cell expansion in droughted plants is abscisic acid dependent. Plant Physiology 118:1507-1515.

Barros, R. S., da S. E. Mota, J. W., Damatta, F. M. and Maestri, M. (1997). Decline of vegetative growth in Coffea arabica L. in relation to leaf temperature, water potential and stomatal conductance. Field Crops Research 54:65-72.

Bates, L. S., Waldren, R. P. and Teare, I. D. (1973). Rapid determination of proline for water stress studies. Plant and Soil 39:205-207.

Carter, T. E. and Rufty, T. W. (1992). Soybean plant introduction exhibiting drought and aluminum tolerance. In Adaptation of Food Crops to Temperature and Water Stress: Proceedings of an International Symposium, Taiwan, 13-18 August, 335-346 (Ed G. G. Kuo). Shanhua, Taiwan: Asian Vegetable Research and Development Genter (AVRDC).

Davies, W. J., Tardieu, F. and Trejo, C. L. (1994). How do chemical signals work in plants that grow in drying soil? Plant Physiology 104:309-314.

de Souza, C. R., Maroco, J. P., dos Santos, T. P., Rodrigues, M. L., Lopes, C. M., Pereira, J. S. and Chaves, M. M. (2003). Partial rootzone drying: regulation of stomatal aperture and carbon assimilation in field grown grapevines (Vitis vinifera cv. Moscatel). Functional Plant Biology 30:653-662.

dos Santos, T. P., Lopes, C. M., Rodrigues, M. L., de Souza, C. R., Maroco, J. P., Pereira, J. S., Silva, J. R. and Chaves, M. M. (2003). Partial rootzone drying: effects on fruit growth and quality of field grown grapevines (Vitis vinifera). Functional Plant Biology 30:663-671.

Fanjul, L., Arreola-R, R. and Mendez-C., M. P. (1985). Stomatal responses to environmental variables in shade and sun-grown coffee plants in Mexico. Experimental Agriculture 21:249-258.

Gaff, D. F. and Loveys, B. R. (1992). Abscisic acid levels in drying plants of a resurrection grass. Transactions of Malaysian Society of Plant Physiology 3(1992):286-287.

Gollan, T., Schurr, U. and E.-D. Schulze. (1992). Stomatal response to drying soil in relation to changes in the xylem sap composition of Helianthus annuus. I. The concentration of cations, anions, amino acids in, and $\mathrm{pH}$ of the xylem sap. Plant Cell and Environment 15:551-559.

Gowing, D. J., Davies, W. J. and Jones, H. G. (1990). A positive root-sourced signal as an indicator of soil drying in apple, Malus domestica Borkh. Fournal of Experimental Botany 41:1534-1540.

Hassan, I. A., Mohd Razi, I., Mohd Mokhtaruddin, M. and Halimi, M. S. (2003). Effect of partial rootzone drying (PRD) on growth, yield and water use efficiency (WUE) of tomatoes on soil less culture. Transactions of Malaysian Society of Plant Physiology 12:128-139. 
Heuer, B. (1999). Osmoregulatory role of proline in plants exposed to environmental stresses. In Handbook of Plant and Crop Stress, 675-695 (Ed M. Pessarakli). New York, NY: Marcel Dekker.

Ismail, M. R., Aziz, M. A. and Hashim, T. (1994). Growth, water relations and physiological change of young durian (Durio zibenthinus Murr) as influenced by water availability. Pertanika fournal of Tropical Agricultural Science 17(3):149156.

Ismail, M. R. and Dalia, S. (1995). Growth, physiological processes and yield of tomatoes grown in different root zone volumes using sand culture. Pertanika fournal of Tropical Agricultural Science 18(2):141-147.

Joshi, A. K. (1999). Genetic factors affecting abiotic stress tolerance in crop plants. In Handbook of Plant and Crop Stress, 795-826 (Ed M. Pessarakli). New York, NY: Marcel Dekker.

Kanechi, M., Uchida, N. U., Yasuda, T. and Yamaguchi, T. (1988). Relationships between leaf water potential and photosynthesis of Coffea arabica L. grown under various environmental conditions as affected by withholding irrigation and re-irrigation. Fapanese Fournal of Tropical Agriculture 32:16-21.

Kang, S., Liang, Z., Hu, W. and Zhang, J. (1998). Water use efficiency of controlled root-division alternate irrigation on maize plants. Agricultural Water Management 38:69-76.

Karpinski, S., Reynolds, H., Karpinska, B., Wingsle, G., Creissen, G. and Mullineaux, P. (1999). The role of hydrogen peroxide and antioxidants in systemic acclimation to photo-oxidative stress in Arabidopsis. In Plant Responses to Environmental Stress, 25-32 (Eds M. F. Smallwood, C. M. Calvert and D. J. Bowles). Oxford, UK: BIOS.

Kirda, C., Cetin, M., Dasgan, Y., Topcu, S., Kaman, H., Ekici, B., Derici, M. R. and Ozguven, A. I. (2004). Yield response of greenhouse grown tomato to partial root drying and conventional deficit irrigation. Agricultural Water Management 69:191-201.

Kitbamroong, G. and Chantachume, Y. (1992). Corn improvement for drought tolerance. In Adaptation of Food Crops to Temperature and Water Stress: Proceedings of an International Symposium, Taiwan, 13-18 August, 354-359 (Ed. C.

G. Kuo). Shanhua, Taiwan: Asian Vegetable Research and Development Center (AVRDC).

Krieg, D. R. (1983). Photosynthetic activity during stress. Agricultural Water Management 7:249-263.

Lawlor, D. H. (1995). The effects of water deficit on photosynthesis. In Environment and Plant Metabolism-Flexibility and Acclimation, 129-156 (Ed N. Smirnoff). Oxford, UK: BIOS.

Lilley, J. M. and Fukai, S. (1994). Effect of timing and severity of water deficit on four diverse rice cultivars II. Physiological responses to soil water deficit. Field Crops Research 37:215-223.

Lima, A. L. S., DaMatta, F. M., Pinheiro, H. A., Totola, M. R. and Loureiro, M. E. (2002). Photochemical responses and oxidative stress in two clones of Coffea canephora under water deficit conditions. Environmental and Experimental Botany 47:239-247.

Liu, F., Jensen, C. R. and Andersen, M. N. (2003). Hydraulic and chemical signals in the control of leaf expansion and stomatal conductance in soybean exposed to drought stress. Functional Plant Biology 30:65-73.

Loewenstein, N. J. and Pallardy, S. G. (1998a). Drought tolerance, xylem sap abscisic acid and stomatal conductance during soil drying: a comparison of young plants of four temperate deciduous angiosperms. Tree Physiology 18:421430.

Loewenstein, N. J. and Pallardy, S. G. (1998b). Drought tolerance, xylem sap abscisic acid and stomatal conductance during soil drying: a comparison of canopy trees of three temperate deciduous angiosperms. Tree Physiology 18:431439.

Maestri, M., Da Matta, F. M., Regazzi, A. J. and Barros, R. S. (1995). Accumulation of proline and quaternary ammonium compounds in mature leaves of water stressed coffee plants (Coffea Arabica and C. canephora). Fournal of Horticultural Science 70:229-233.

Meinzer, F. C., Saliendra, N. Z. and Crisosto, C. H. (1992). Carbon isotope discrimination and gas exchange in Coffea Arabica during adjustment to different soil moisture regimes. Australian Fournal of Plant Physiology 19(2):171184.

Mingo, D. M., Theobald, J. G., Bacon, M. A., Davies, W. J. and Dodd, I. C. (2004). Biomass allocation in tomato (Lycopersicon esculentum) plants grown under partial root zone drying: enhancement of root growth. Functional Plant Biology 31:971-978.

Nagy, Z., Tuba, , and Z. Csintalan, Zs, . (1993). Ecophysiological responses of different density maize stands under drought stress and during recovery. Photosynthetica 28(3):351-359.

Naqvi, S. S. M. (1999). Plant hormones and stress phenomena. In Handbook of Plant and Crop Stress, $709-730$ (Ed M. Pessarakli). New York, NY: Marcel Dekker.

Navari-Izzo, F. and Rascio, N. (1999). Plant response to water-deficit conditions. In Handbook of Plant and Crop Stress, 231-270 (Ed M. Pessarakli). New York, NY: Marcel Dekker. 
Parimala, P. and Muthuchelian, K. (2011). Antioxidative responses and expression of insecticidal proteins in Bt cotton under high irradiance. Fournal of Stress Physiology \& Biochemistry 7(3):201-211.

Price, M., Jalaluddin, Md. and Dilday, R. H. (1992). Evaluation of rice germplasm for drought tolerance. In Adaptation of Food Crops to Temperature and Water Stress: Proceedings of an International Symposium, Taiwan, 13-18 August, 347-353 (Ed. C. G. Kuo). Shanhua, Taiwan: Asia Vegetable Research and Development center (AVRDC).

Pugnaire, F. I., Serrano, L. and Pardos, J. (1999). Constraints by water stress on plant growth. In Handbook of Plant and Crop Stress, 271-283 (Ed M. Pessarakli). New York, NY: Marcel Dekker.

Rhizopoulou, S., Meletiou-Christou, M. S. and Diamantoglou, S. (1991). Water relations for sun and shade leaves of four Mediterranean Evergreen Sclerophylls. Fournal of Experimental Botany 42(238):627-635.

Rosario, D. A., Ocampo, E. M., Sumague, A. C. and Paje, M. C. M. (1992). Adaptation of vegetable legumes to drought stress. In Adaptation of Food Crops to Temperature and Water Stress: Proceedings of an International Symposium, Taiwan, 13-18 August, 360-371 (Ed C. G. Kuo). Shanhua, Taiwan: Asian Vegetable Research and Development Center (AVRDC).

Saliendra, N. Z., Sperry,J. S. and Comstock, J. P. (1995). Influence of leaf water status on stomatal response to humidity, hydraulic conductance, and soil drought in Betula occidentalis. Planta 196:357-366.

SAS (1988). SAS/STAT user's guide for personal computer. Version 6.03. SAS Institute Inc., Cary, North Carolina, USA.

Siamak, S. B., Sariah, M., Zakaria, W., Sreeramanan, S. and Maziah, M. (2012). In vitro selection and characterization of water stress tolerant lines among ethyl methanesulphonate (EMS) induced variants of banana (Musa spp., with AAA genome). Australian Fournal of Crop Science 6(3):567-575.

Smirnoff, N. (1995). Antioxidant systems and plant response to the environment. In Environment and Plant MetabolismFlexibility and Acclimation, 217-243 (Ed. N. Smirnoff). Oxford, UK: BIOS.

Stoll, M., Loveys, B. and Dry, P. (2000). Hormonal changes induced by partial rootzone drying of irrigated grapevine. Journal of Experimental Botany 51:1627-1634.

Tardieu, F. and Davies, W. J. (1992). Stomatal response to abscisic acid is a function of current plant water status. Plant Physiology 98:540-545.

Tardieu, F. and Davies, W. J. (1993). Integration of hydraulic and chemical signaling in the control of stomatal conductance and water status of droughted plants. Plant Cell and Environment 16:314-349.

Tardieu, F., Katerji, N., Bethenod, O., Zhang, J. and Davies, W. J. (1991). Maize stomatal conductance in the field: its relationship with soil and plant water potentials, mechanical constraints and ABA concentration in the xylem sap. Plant Cell and Environment 14:121-126.

Tesfaye, S. G., Ismail, M. R., Kausar, H., Marziah, M. and Ramlan, M. F. (2013a). Plant water relations, crop yield and quality of arabica coffee (Coffea arabica) as affected by supplemental deficit irrigation. International fournal of Agriculture and Biology 15:665-672.

Tesfaye, S. G., Ismail, M. R., Kausar, H., Marziah, M. and Ramlan, M. F. (2013b). Plant water relations, crop yield and quality in coffee (Coffea arabica L.) as influenced by partial root zone drying and deficit irrigation. Australian fournal of Crop Science 7(9):1361-1368.

Tesfaye, S. G., Razi, I. M. and Marziah, M. (2008). Effects of deficit irrigation and partial root zone drying on growth, dry matter partitioning and water use efficiency in young coffee (Coffeaa arabica L.) plants. Fournal of Food, Agriculture and Environment 6(3-4):132-137.

Thompson, D. S., Wilkinson, S., Bacon, M. A. and Davies, W. J. (1997). Multiple signals and mechanisms that regulate leaf growth and stomatal behavior during water deficit. Physiologia Plantarum 100:303-313.

Trejo, C. L. and Davies, W. J. (1991). Drought-induced closure of Phaseolus vulgaris stomata precedes leaf water deficit and an increase in xylem ABA concentration. Fournal of Experimental Botany 42:1507-1516.

Volkmar, K. M. and Woodbury, W. (1995). Plant-water relationships. In Handbook of Plant and Crop Physiology, 23-43 (Ed M. Pessarakli). New York, NY: Marcel Decker.

Wakrim, R., Wahbi, S., Tahi, H., Aganchich, B. and Serraj, R. (2005). Comparative effects of partial root drying (PRD) and regulated deficit irrigation (RDI) on water relations and water use efficiency in common bean (Phaseolus vulgaris L.). Agriculture, Ecosystems and Environment 106:275-287.

Willson, K. C. (1999). Coffee, Cacoa and Tea. Cambridge, UK: CABI.

Zegbe-Dominguez, J. A., Behboudian, M. H., Lang, A. and Clothier, B. E. (2003). Deficit irrigation and partial rootzone drying maintain fruit dry mass and enhance fruit quality in 'Petopride' processing tomato (Lycopersicon esculentum, Mill.). Scientia Horticulturae 98:505-510. 